\title{
Students' Proficiency and Textual Computer Gloss Use in Facilitating Vocabulary Knowledge
}

\author{
Mohamad A. Yusuf ${ }^{1}$, Tam S. $\operatorname{Sim}^{1} \&$ Su'ad A. ${ }^{1}$ \\ ${ }^{1}$ Faculty of Languages and Linguistics, University of Malaya, Kuala Lumpur, Malaysia \\ Correspondence: Mohamad A. Yusuf, No. 44, Jalan Lang, Rifle Range 30000, Ipoh, Perak, Malaysia. E-mail: \\ mohdali990@yahoo.com
}

Received: August 6, 2014 Accepted: September 10, 2014 Online Published: October 23, 2014

doi:10.5539/elt.v7n11p99 URL: http://dx.doi.org/10.5539/elt.v7n11p99

\begin{abstract}
Learning vocabulary forms a major part for any language learner. Apart from direct teaching of vocabulary, language teachers are always searching for ways to increase their students' vocabulary to enable them to use the language more effectively. Therefore, this study sets out to investigate whether the use of computer textual glosses can aid vocabulary development. With a sample of 99 English as second language students, this study examines whether a computer-aided textual glosses embedded in a narrative text is able to aid students in developing their vocabulary knowledge. Using ANOVA and descriptive statistics, it was found out that students with different language proficiency levels used the gloss in a similar pattern. The similarity was that there were gains after immediate use of the glosses but the gains were not maintained over time. High proficiency students made the most gains followed by mid and low proficiency students. What can be learnt from this study is that computer textual glosses can be used to develop students' vocabulary knowledge in the short term. However, this should be supplemented with other vocabulary teaching/learning activities for more robust vocabulary knowledge development. The implications of measuring vocabulary knowledge by using vocabulary tests in the study could have resulted in the students having more gain in productive vocabulary knowledge compared to receptive vocabulary.
\end{abstract}

Keywords: computer textual gloss, proficiency level, vocabulary knowledge

\section{Introduction}

A language student faces many challenges in his or her quest to learn another language. Among the challenges are learning the structures and vocabulary of the language. These are needed by them to allow students to use and comprehend information in the language that they are learning. The incomprehensibility of information may be attributed to many factors such difficulty of text, lack of background knowledge and linguistic constraints such as lack of vocabulary. The lack of vocabulary can be a major obstacle for second language learners as researchers such as Grabe (1991), Haynes and Baker (1993), Laufer (1997), Read (2004) have found out that vocabulary is the main factor which can impede or enhance comprehension. Read (2004) writes that second language learners are aware that limitations in their vocabulary hinders them in their communication in the target language as "lexical items carry the basic information load of the meanings they wish to comprehend and express" (p. 146). This is the reason why Read justifies that vocabulary is important for students to acquire as compared to other features of the language. Therefore, it is important and useful to find ways to effectively develop students' vocabulary knowledge. It can complement teaching vocabulary as teaching is time consuming and as Parry (1993) notes that "it is simply not economic to spend precious minutes on items whose chances of reoccurrence may be low" (p. 2).

With that as a background, this study examines whether gloss use is able to help students develop their vocabulary knowledge. It has been documented that gloss use is beneficial for vocabulary learning. Nation (2001) describes three main reasons why glosses are useful to learners. His first reason is that learners are able to handle difficult texts as a glossary of the unfamiliar words are provided. Secondly, with the aid of glosses, learners will not guess the meanings of the words wrongly as the correct meanings are given. Thirdly, he affirms that glosses do not intrude into the learners' reading where using a dictionary may interrupt the reading process.

The purpose of the study is to examine how students with different proficiency levels use a computer-aided textual gloss and to find out what kind of gains they had obtained in their vocabulary knowledge. Gloss use in 
this study is defined as the clicking done on the words which were glossed. This would allow the students to consult the glosses which contained the meanings of the unfamiliar words. The glosses which were created were textual ones, at both word and sentence levels in the students' L1 which is Bahasa Melayu (BM) and English. This study had not incorporated multimedia glosses as textual glosses are more straightforward and simpler to design compared to multimedia type of glosses. Proficiency levels of the students were determined by the grade they had obtained in English in a national level examination, Sijil Pelajaran Malaysia (SPM). The grades were then categorised as low, mid and high levels of proficiency.

Vocabulary knowledge is operationalised as knowing the meaning of a word productively and receptively. In other words, students should know the meaning of the words as well as to produce the right form of the words. This knowledge is measured in the study by specifically designing productive and receptive vocabulary tests. To sum up, the independent variables in the study are proficiency and gloss use, while the dependent variable is vocabulary knowledge. Thus, the study is designed in search for the answers to the following research questions:

1) How do students of different levels of proficiency use computer textual glosses?

2) How does this use affect their vocabulary knowledge?

3) What type of gains are made in the type of vocabulary knowledge

a) Will the knowledge be maintained over time?

\section{Literature Review}

\subsection{Proficiency and Gloss Use}

From the studies on gloss use which have been reviewed, it is revealed that some researchers have pointed out that the proficiency level of the learners does play a role in their look-up behaviour. For example, Ercetin (2001) states that, "second language learners interact with text differently based on their proficiency level and prior knowledge" (p. 70).

Jacobs, Dufon, and Hong (1994) also found that the effectiveness of glosses varies according to the learners' language proficiency. They argue that glosses have a different impact on learners with different proficiency levels in the L2. In terms of vocabulary learning, they found out that higher proficiency learners recalled more vocabulary if they had accessed to gloss words. On the other hand, Li (2010) who examined 20 Chinese ESL learners' vocabulary retention after they had read a text with and without access to computer-mediated English monolingual and English-Chinese bilingual dictionaries revealed that both computer-mediated glosses and bilingual dictionaries were effective for learners with lower proficiency levels.

Yoshii and Flaitz (2002) also considered proficiency level of the learners who were at beginning and intermediate stages. They found out that there were no significant differences between the two levels in the rate of change between the immediate and delayed test scores. Knight (1994); Yoshi (2006) and Abraham (2008) analyzed gloss use behaviour and have concluded that the language ability of the learners affects the way they use the gloss, that is, it has a role in the learners' look-up behaviour. Their interpretations of the gloss use have implicated language ability of learners but these researchers have not delved deeper into the issue. Providing further evidence of the effect of proficiency and gloss use, Yun (2011) who carried out meta-analysis of 10 studies on gloss use on reading comprehension and vocabulary learning revealed that the variable of learner proficiency was found to be statistically significant as glosses made an impact to L2 vocabulary acquisition on beginning learners.

\subsection{Vocabulary Knowledge}

Defining vocabulary knowledge is complicated as the definition of vocabulary knowledge varies among researchers. Clearly, vocabulary knowledge has been defined differently by researchers. Nation (2001), for instance, writes that vocabulary knowledge can be defined as the sum of interrelated subknowledges which involves knowing its "form, meaning and use" (p. 26). From these three perspectives, knowledge of a word expands to knowing how the word is spoken, written, its form and meaning, concept and referents, its associations, grammatical functions, collocations as well as its constraints on use. Furthermore, vocabulary knowledge is looked upon as a continuum comprising several levels. The first level can be considered as superficial familiarity of the words by researchers such as Faerch, Haastrup, and Phillipson (1984) and Palmberg (1987). At the next level is one of the most common distinctions of vocabulary knowledge which is "receptive and productive knowledge" (Schmitt, 2010, p. 80). Nation (2001) elaborates that receptive knowledge is needed to deal with words in listening and reading. On the other hand, productive knowledge is called active knowledge and it is needed to use word in speaking and writing. 


\subsection{Vocabulary Learning}

Schmitt (2002) writes that for most first language vocabulary learning, a large part of the input comes from listening and reading. The same can also be applied to second language learners, where Read (2004) states that second language learners acknowledge the importance of vocabulary in the target language. Furthermore, second language learners need to be exposed to different modalities such as written or listening to get input in order to acquire new vocabulary. Two different perspectives are put forth next to discuss vocabulary learning.

\subsubsection{Noticing, Retrieval and Generation}

From Nation's (2001) broad research on vocabulary learning, he suggests that there are three stages which are required for vocabulary acquisition. There are noticing, retrieval and generative. The first is noticing where the learner notices that there is a word which he or she is unfamiliar with. The second is Retrieval where there is a possibility of remembering words so that they can be retrieved by the learner, and the third is generating the vocabulary retrieved. Nation makes two distinctions of retrieval: receptive retrieval and productive retrieval. Receptive retrieval is when learners perceive the form and retrieve the meaning, while the opposite is true for productive, that is, learners have the meaning and retrieve the form. Nation puts across that both types of retrieval are important, however he feels that productive retrieval is better for vocabulary learning. The final concept is generative where learners are able to use the words learnt in a different grammatical form, in different contexts or with a new meaning (Alum, 2004).

\subsubsection{Involvement Load Hypothesis}

Another vocabulary learning perspective which can also be applied to the interaction between the computer and the learner is provided by Laufer and Hultsijn (2001). They have termed it as the Involvement Load Hypothesis which posits that tasks which induce higher involvement from the learner. It works on the premise of the learners' level of processing, that is, when the learner processes the vocabulary more, the eventuality for the vocabulary to be learnt and retained is increased. Laufer and Hulstijn (2001) suggest that the involvement of vocabulary learning has three components. The three components are: Need, Search and Evaluation. Need is the requirement to understand a linguistic feature in order to perform a task, for example, need for a meaning of a word in a reading comprehension task. Search is to look for the meaning, which could be looking up the word in a dictionary or even use a gloss. Finally, Evaluation is to evaluate if the word can be suitably used in certain contexts. This Evaluation stage is cognitive type of interaction, one which Chapelle (2003) terms as "Intra" that is within the learner's mind. The involvement load can be triggered by the learner first noticing the lexical item, the amount of time spent engaging with the lexical item in terms of interaction thus increasing the engagement with the lexical item. According to Schmitt (2010), these are among the factors that can facilitate vocabulary learning. He adds that "the more a learner engages with a new word, the more likely he/she is to learn it" (p. 26).

\subsection{Measuring Vocabulary}

It can be seen that research on vocabulary is a complex matter, whether it is in defining the vocabulary construct and even pinning a theory to learning vocabulary. This complexity continues when it comes to measuring vocabulary knowledge. It is not easy to measure vocabulary (Nation, 2001). This claim by Nation is aptly described by Schmitt (2010) who states that:

It is virtually impossible to measure all the word-knowledge aspects for words for a least three reasons. The first is that many of the word knowledge aspects do not have accepted methods of measurement. A second reason has to do with time... a test battery for word would be extremely unwieldy and time consuming. A third reason is related to the difficulty of controlling for cross-test effects. (p. 79)

Nevertheless, efforts to provide justifications for the types of tests used and to explicitly state what they measure and to what extent have to be in place. A good starting point would be to define the construct vocabulary as explained in the earlier section. The operationalization of the vocabulary construct is to make a distinction between types of vocabulary knowledge tested. As there can be different types of vocabulary knowledge there is a need for multiple tests to measure varied aspects of vocabulary knowledge. Another use of multiple tests for vocabulary is because a single test would not be able to measure every aspect of word knowledge (Milton, 2009). Different types of tests are developed to capture types of vocabulary knowledge of learners with varying degrees of sensitivity. Thus, in this study two separate tests were designed to capture the students' productive and receptive vocabulary knowledge. 


\section{Methodology}

\subsection{Participants}

One hundred and seventeen students took part in the initial stage of this research. They were diploma students from 4 intact classes of a public university in Malaysia. They were in their first semester of their studies and their ages were from 18-20 years old. These tertiary English as a second language (ESL) students were chosen as knowledge of word meanings and the ability to access that knowledge efficiently was recognized as important factors in reading and listening comprehension, especially as learners progress to higher or tertiary level (Chall, 1983). The final number of students who fully completed the research process was 99 students as some students did not complete the delayed test while some students' interaction data with the glosses were not recorded by the tracking device in the computers.

\subsection{Materials}

A short narrative text titled "A Scary Night" was adopted from a study by Yoshi (2006) and uploaded on the internet. In the text, vocabulary items that were unfamiliar to the students were glossed. The vocabulary items are glossed in two ways. One is for the researchers and their two colleagues to identify the words which they think the students may need help in finding out the meaning.

Secondly, a group of students with the same background as those in the study were given the text in the form of pencil-and-paper and asked to circle the words that they found difficult and did not understand. Thirteen words were finally glossed in BM and English. The type of glosses which were created was textual ones at word and sentence levels. The word gloss provided definitional meaning of the words while sentence type of glosses provided meaning in contextualised form.

To measure the vocabulary knowledge, two sets of tests were designed. To test receptive vocabulary knowledge, a multiple choice type of test was set. In this test, the students had to choose the correct definition of the meaning of the word. For the productive vocabulary knowledge, students had to fill in the correct word into the blank of each sentence. In each blank, the initial letter(s) of the word was/were provided to help the learners provide the targeted words instead of using other words. Both the tests contained 13 questions corresponding to the 13 glosses words in the text.

\subsection{Research Procedure}

The research was carried out following a set procedure. Firstly, the students were asked to state their SPM English grade before the experiment. From this, the students were stratified according to their grades which were then classified into three categories, low, mid and high proficiency levels. The next step was for the students to be in the language laboratories where they accessed the website which contained the story. They were told to read the story and they could click on the words which were glossed (using a different colour from the rest of the text). When the words were clicked, the meanings of the words were given either in BM, English or at word and sentence levels.

After reading the text, the students were given both the productive and receptive vocabulary tests. These tests formed the immediate test. After three weeks, the students were given the same set of vocabulary tests. For this delayed test, the items in the tests were not in the same sequence as in the immediate test. This was done to avoid the test effects of the earlier immediate test.

\section{Results}

The data obtained from the study was analysed using ANOVA and straight forward descriptive statistics. Firstly, data how the students interacted or used the glosses were analyzed. Secondly, data were examined according to the proficiency level and the type of vocabulary knowledge.

\subsection{Gloss Use of Students with Different Proficiency Levels}

A one way analysis of Variance (ANOVA) was conducted to assess whether there were differences between the total number of clicks indicating gloss use among the students with different proficiency levels. The dependent variable in each ANOVA was the total number of clicks and the independent variable was the proficiency levels. If significant results were found, then Tukey's post -hoc multiple comparisons were further computed to determine where the difference between the proficiency levels.

Preliminary assumption testing was conducted to check for normality and homogeneity of variance of the dependent variable. The results showed no serious departure from the two assumptions for all proficiency levels. Table 1 indicates the mean and standard deviation of the number of clicks at low, mid and high proficiency level. The results of one way ANOVA are presented in Table 2 
Table 1. Mean and standard deviation for number of clicks in each proficiency level

\begin{tabular}{lllll}
\hline & $\mathrm{N}$ & Mean & Std. Deviation & Std. Error \\
\hline LOW & 30 & 10.2333 & 7.01566 & 1.28088 \\
MID & 39 & 11.6923 & 6.32103 & 1.01218 \\
HIGH & 30 & 9.5667 & 5.27638 & .96333 \\
Total & 99 & 10.6061 & 6.25613 & .62876 \\
\hline
\end{tabular}

ANOVA and post-hoc comparisons both indicated that in low proficiency level there was no statistically significant difference between different proficiency levels in the number of clicks. F $(2,96)=1.056$ P-value $=$ 0.352. This indicates that the gloss use of the students in the different proficiency levels was almost the same.

Table 2. ANOVA for number of clicks at different proficiency levels

\begin{tabular}{lllll}
\hline & df & Mean Square & F & Sig. \\
\hline Between Groups & 2 & 41.298 & 1.056 & .352 \\
Within Groups & 96 & 39.094 & & \\
Total & 98 & & & \\
\hline
\end{tabular}

\subsection{Proficiency Levels and Type of Vocabulary Knowledge}

To investigate the above variables, mean test scores of the students in the different proficiency levels and type of vocabulary knowledge, which is productive and receptive vocabulary knowledge were examined. Table 3 shows the mean scores across immediate test and delayed post-test in different proficiency levels for the productive vocabulary knowledge.

Table 3. Mean scores and standard deviation for production tests

\begin{tabular}{lllll}
\hline & Level of Proficiency & Mean & Std. Deviation & N \\
\hline Vocabulary & Low & 11.67 & 1.093 & 30 \\
productive test 1 & Mid & 12.21 & .923 & 39 \\
& High & 12.70 & .535 & 30 \\
& Total & 12.19 & .965 & 99 \\
Vocabulary & Low & 10.60 & 2.660 & 30 \\
productive test 2 & Mid & 10.54 & 1.958 & 39 \\
& High & 12.20 & .961 & 30 \\
& Total & 11.06 & 2.104 & 99 \\
\hline
\end{tabular}

Information from the table suggests that the high proficiency level group gained more than the two other groups. Figure 1 shows the interaction plot of the estimated marginal mean scores across test 1 and test 2 in different proficiency levels. An inspection of the results and Figure 1 reveals that averaged across the three tests, those with high proficiency levels had the highest test scores, followed by those with mid proficiency level. The least test scores group was those with low proficiency levels. But all three groups experienced the same trend (parallel lines), where there was increase in the immediate test followed by a decrease in the delayed test. 


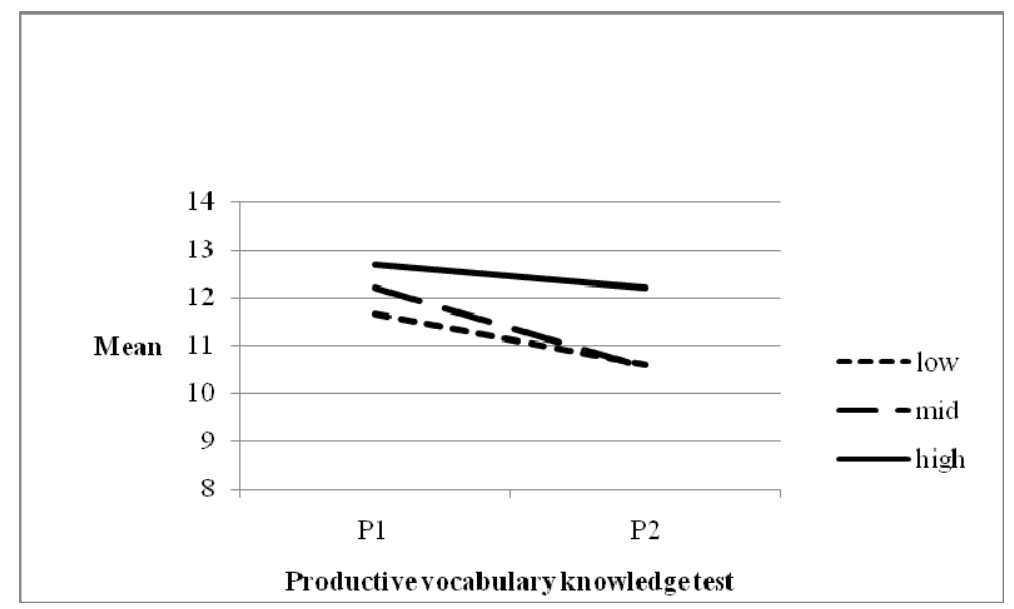

Figure 1. Productive vocabulary knowledge and proficiency levels

Table 4. Mean sores and standard deviation for word receptive tests in each proficiency level

\begin{tabular}{lllll}
\hline & Level of proficiency & Mean & Std. Deviation & $\mathrm{N}$ \\
\hline Word receptive test 1 & Low & 7.6333 & 2.38506 & 30 \\
& Mid & 10.1026 & 1.83238 & 39 \\
& High & 12.1000 & 1.29588 & 30 \\
& Total & 9.9596 & 2.55917 & 99 \\
Word receptive test 2 & Low & 6.3000 & 2.08690 & 30 \\
& Mid & 8.6667 & 2.09427 & 39 \\
& High & 11.6000 & 1.40443 & 30 \\
& Total & 8.8384 & 2.80927 & 99 \\
\hline
\end{tabular}

Figure 2 shows the interaction plot of the estimated marginal mean scores across word receptive test 1 and word receptive test 2 in different proficiency levels. The results indicated that students with high proficiency levels had the best test scores than mid and low levels, averaged across the two tests.

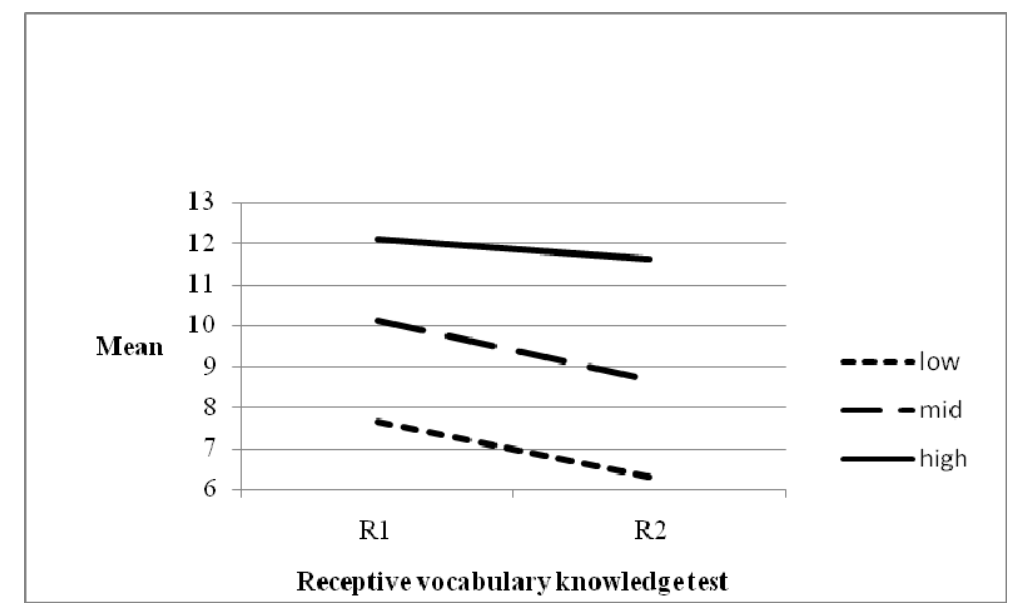

Figure 2. Receptive vocabulary knowledge and proficiency levels

As for the variable of proficiency, it can be seen that high proficiency students benefitted the most from glosses in both types of vocabulary knowledge, that is, productive and receptive. Again what can be observed is that all proficiency levels had a similar pattern of development and type of vocabulary knowledge gained meaning that 
high proficiency students made the most gains, followed by mid and low proficiency level students. Parallel to the patterns in productive vocabulary knowledge, the high proficiency students benefitted the most from interaction with the glosses in receptive knowledge followed by the mid and low proficiency students. Therefore it can be assumed that different levels of proficiency had used the glosses in a standard manner but it had affected their vocabulary knowledge in different ways.

\section{Discussion}

\subsection{Language Proficiency and Gloss Use}

From the findings, it can be concluded that language proficiency effects gloss use. This is in line with the finding from Cheng and Good (2009). In their study, all proficiency levels gained from the use of glosses but the benefits were not equal. Here, it was seen that high proficiency learners gained the most, followed by mid and low proficiency learners. This observation does seem to concur with Watanabe's (1997) explanation that even with glosses which were comprehensible, learners with small vocabulary size would not benefit. In his study's context a small vocabulary size may be assumed to mean low proficiency. The higher proficiency learners performed better in the vocabulary tests could also be attributed to their competence in the L2 and they were able to maximize the use of the glosses for their benefit. This is similar to what Jacobs et al. (1994) and Yun (2011) had found in their study. The results from Jacobs' research are consonant with what has been found in this study where high proficiency students made the most gains in vocabulary knowledge compared to the mid and low proficiency students.

What can be learnt from the results is that it is important to consider learners' proficiency levels when designing glosses as learners in varying language proficiency levels benefit from gloss use differently. The researchers discovered that high proficiency level learners gained the most in productive and receptive knowledge. This finding fits into the following observation by Groot (2000), "One might argue that high level learners have meta-cognitive strategies at their disposal which make their acquisition of new vocabulary much less dependent on externally imposed learning conditions than is the case for low level learners" (p. 21).

It is also documented (Cheng \& Good, 2009; Jacobs, Dufon, \& Hong, 1994) that high proficiency students with bigger vocabulary would consult lesser words compared to students in low proficiency with smaller vocabulary. The high proficiency students were able to take advantage of the glosses which provided more contexts for vocabulary development. This is in line with Schmitt's (2010) claim that language proficiency determines to what degree learners can take advantage of any contextualization in language learning tasks or tests.

In the case for low proficiency learners, the retention loss is consistent with the study by Abraham (2008) who also discovered that beginner L2 learners experienced a significant amount of vocabulary retention loss. The findings in this study are similar to the findings in Watanabe's (1997) study. In that study it was found out that even with glossing, learners with small vocabulary size would not be able to effectively use the glosses provided. It could be interpreted that low proficiency students were the ones who had small vocabulary size. Finally, it is emerging that proficiency has a role in relation to gloss use. It is clear that students' proficiency levels and their use of glosses impact vocabulary knowledge development in different ways.

\subsection{Learning Vocabulary}

Related to the use of glosses as in this study, both approaches reviewed earlier are applicable for vocabulary learning. For instance, in keeping to Nation's (2001) approach, the first element is met when students notices the gap in their linguistic knowledge, which prompted them to retrieve the meaning. In this study, it would be the clicking and using the glosses. Finally, in the generative stage, the students generated the vocabulary items in the vocabulary tests.

As for the Involvement Load theory, the three major components of the theory were also present in this study. Firstly, the students read the text and met the unfamiliar words which triggered a need for them to understand the words. Secondly, search was in the form of clicking on the target words to access the glosses, and thirdly, the evaluation stage where the students evaluated the suitability of words for use in the vocabulary tests.

The elements in both approaches described above are evident in this study. However, it appears that Nation's Vocabulary Learning approach is more suited to explain the vocabulary learning in this study with the elements of noticing, retrieval and generative, in tandem with noticing, gloss use and output in the form of the tests as manifested in this study. As for Hultsjin's Involvement Load theory (2001) it may not be applicable here because the involvement load or processing of the students with the target vocabulary is insufficient for effective learning. It can be assumed that interactions with the textual gloss and the subsequent vocabulary tests in the study did not provide enough involvement for the students. Furthermore, the study did not attempt to document the level of 
processing of the students.

\subsection{Vocabulary Knowledge}

The literature on vocabulary learning shows evidence that receptive knowledge is more readily gained when compared to productive knowledge. It is documented that the ideal vocabulary learning cline should move from a receptive stage to more productive use of vocabulary (Laufer \& Paribakht, 1998; Laufer \& Goldstein, 2004; Ortega, 2009). In simple terms, it means learners can recognise more words than they can actually use. However, this trend of development was not seen in this study.

From the data, it can be seen that students gained more productive vocabulary knowledge compared to receptive knowledge. This mismatch could have resulted from the tests used in the study. What could have transpired resulted from the nature of the tests used in the study. One probable reason was that the productive test with its gap-filling and initial letters format could have given more readily clues of the right answers to the students. The next reason was that the sentence-level format may have provided the necessary context for the students to arrive at the right answer, thus they were able to score higher in the productive test. It could also be reasoned out that the lenient scoring guide could also be the reason the students did better in the productive test. The scoring guide allowed for marks to be awarded even though the inflections were not correct. In contrast, the multiple choice format of the test measuring receptive vocabulary knowledge without any context may have been difficult for the students. They were unable to provide the correct meaning of the target words. Hence the disparity in performance of the students in these two tests. The conclusion that can be made is that the design and format of the tests could play a significant role in the outcome of the tests.

It has been shown that vocabulary learning is certainly a dynamic process. It is seen that vocabulary development is possible however as in most kinds of learning, it is common that there will be instances of attrition (Schmitt, 2010). In fact, according to him vocabulary knowledge is more susceptible to be lost when compared to other linguistic elements such as phonology or grammar. He reasons that this is because vocabulary is made up of individual units instead of a series of rules as in grammar, hence the tendency for backsliding to occur is greater. This phenomenon is also present in this study. The vocabulary knowledge gained was not sustained after three weeks.

\subsection{Implications to Pedagogy}

Textual glossing as in this study may enhance vocabulary learning in the short-term. It would seem that learning vocabulary through computer-textual glosses can be an interim solution to the teaching and learning of vocabulary. Glossing of unfamiliar or difficult words can act as an autonomous vocabulary episode for the students to be later complemented with direct teaching or some other learning vocabulary activity.

For retention of knowledge however, more robust and "pushed output" tasks have to be designed to sustain knowledge from the initial gain made by textual-only gloss use. The tests measuring the productive and receptive knowledge in this study did not allow the learners sufficient opportunities for them to produce output. Therefore for more long-term gains by teaching, more tasks are designed to create more instances for noticing, and processing which would enable favourable long-term gains in vocabulary knowledge.

\section{Conclusion}

It can be concluded that proficiency level of students does influence gloss use and vocabulary knowledge. From this study, there appears to be not much difference in the way the students with different proficiency levels use the gloss; with initial gains and loss of vocabulary knowledge in the long term. In addition, students with different proficiency levels benefited differently from gloss use. As expected students with high proficiency level made the most gains in vocabulary knowledge followed by mid and low proficiency levels students, and both productive and receptive knowledge. Therefore textual computer glosses can be used to initiate vocabulary learning but for more sustained vocabulary knowledge, other vocabulary teaching/learning activities have to be in place. It was also discovered that students seem to gain more of productive than receptive vocabulary knowledge. Although this can be attributed to the gloss use, the researchers point to the kinds of tests used in this study that measured the productive and receptive vocabulary knowledge. The researchers cautiously conclude that the type of tests used may influence the type of vocabulary knowledge.

\section{References}

Abraham, L. B. (2008). Computer-mediated glosses in second language reading Comprehension \& vocabulary learning: A Meta-analysis. Computer Assisted Language Learning, 3(21), 199-226.

Allum, P. (2004). Evaluation of CALL: Initial vocabulary learning. ReCALL, 16(2), 488-501. 
Chall, J. S. (1983). Stages of reading development. New York: Harcourt Brace.

Chapelle, C. A. (2003). English language learning \& technology. Amsterdam: John Benjamins Publishing Co.

Cheng, Y. H., \& Good, R. L. (2009). L1 glosses: Effects on EFL learners' reading comprehension and vocabulary retention. Reading in a Foreign Language, 21, 119-142.

Ercetin, N. (2001). Second language reading in a hypermedia environment: The role of proficiency, annotation use, text format, \& prior knowledge (Unpublished doctoral dissertation). University of Arizona, Tuscon.

Færch, C., \& Haastrup, K. R. P. (1984). Learner language \& language learning. Clevedon: Multilingual matters.

Grabe, W. (2004). 3. Research on teaching reading. Annual Review of Applied Linguistics, 24(1), 44-69.

Groot, P. J. M. (2000). Computer assisted second language vocabulary acquisition. Language Learning and Technology, 4(1), 60-81. Retrieved September 10, 2011, from http://lt.msu.edu.vol4num1/groot/defaultt.html

Haynes, M., \& Baker, I. (1993). American and Chinese readers learning from lexical familiarization in English texts. Second Language Reading and Vocabulary Learning, 130-152.

Jacobs, G., Dufon, P., \& Hong, F. (1994). L1 \& L2 vocabulary glosses in L2 reading passages: Their effects for increasing comprehension \& vocabulary knowledge. Journal of Research in Reading, 17(1), 19-32.

Knight, S. (1994). Dictionary: The tool of last resort in foreign language reading? A new perspective. The Modern Language Journal, 78, 285-299.

Laufer, B. (1997). The lexical plight in second language reading: Words you don't know, word you think you know and words you can't guess. In J. Coady, \& T. Huckin (Eds.), Second language vocabulary acquisition: A rationale for pedagogy. Cambridge: Cambridge University Press.

Laufer, B., \& Paribakht, T. S. (1998). The relationship between passive and active vocabularies: Effects of language learning context. Language Learning, 48(3), 365-391.

Laufer, B., \& Hulstijn, J. (2001). Incidental vocabulary acquisition in a second language: The construct of task-induced involvement. Applied Linguistics, 22(1), 1-26.

Laufer, B., \& Goldstein, Z. (2004). Testing vocabulary knowledge: Size, strength \& computer adaptiveness. Language Learning, 54(3), 399-436.

Li, J. (2010). Learning vocabulary via computer-assisted scaffolding for text processing. Computer Assisted Language Learning, 23(3), 253-275.

Milton, J. (2009). Measuring second language vocabulary acquisition. Bristol: Multilingual Matters.

Nation, P. (2001). Learning vocabulary in another language. Cambridge: Cambridge University Press.

Ortega, L. (2009). Understanding second language acquisition. London: Hodder Education.

Parry, K. J. (1993). Too many words: Learning the vocabulary of an academic subject. In T. Huckin, M. Haynes, \& J. Coady (Eds.), Second language reading \& vocabulary learning (pp. 109-129). Norwood, NJ: Ablex.

Schmitt, N. (Ed.). (2002). An introduction to applied linguistics. London: Arnold.

Schmitt, N. (2010). Researching vocabulary. A vocabulary research manual. Hampshire: Palgrave Macmillan.

Watanabe, Y. (1997). Input, intake, and retention: Effects of increased processing on incidental learning of foreign language vocabulary. Studies in Second Language Acquisition, 19(3), 287-307.

Yoshii, M., \& Flaitz, J. (2002). Second language incidental vocabulary retention: The effect of picture \& annotation types. CALICO Journal, 20(1), 33-58.

Yoshii, M. (2006). L1 \& L2 glosses: Their effects on incidental vocabulary learning. Language Learning \& Technology, 3(10), 85-101.

Yun, J. (2011). The effects of hypertext glosses on L2 vocabulary acquisition: A meta analysis. Computer Assisted Language Learning, 1(24), 39-58.

\section{Copyrights}

Copyright for this article is retained by the author(s), with first publication rights granted to the journal.

This is an open-access article distributed under the terms and conditions of the Creative Commons Attribution license (http://creativecommons.org/licenses/by/3.0/). 